\title{
An Empirical Application of the Trade-0ff Model for Companies in the Dow Jones Industrial Average
}

\author{
José L. Gallizo', Ana Vendrell Vilanovaํㅜ, Manuel Salazar² \\ ${ }^{1}$ Department of Business Administration, University of Lleida, Lleida, Spain \\ ${ }^{2}$ PhD IEDE Business School, Santiago de Chile, Chile \\ Email: gallizo@aegern.udl.cat
}

Received 3 November 2014; revised 30 November 2014; accepted 10 December 2014

Copyright (C) 2014 by authors and Scientific Research Publishing Inc.

This work is licensed under the Creative Commons Attribution International License (CC BY). http://creativecommons.org/licenses/by/4.0/

c) (i) Open Access

\section{Abstract}

This study develops a dynamic model of optimization of the value of the company following the postulates of the theory of Trade-Off. The model includes Bystrom formulation for calculating the cost of bankruptcy in the search the optimal debt. Our model is innovative in several respects: 1) raises calculate the cost of bankruptcy easily. This model is easy to implement in firms 2) calculates the cost of debt endogenously. 3) The calculation is dynamic. We determine the cost of debt and the cost of capital for each unit of additional debt. The proposed model has been applied to the companies that make up the Dow Jones Industrial Average (DJIA) in 2007. We have used consolidated financial data from 1996 to 2006, published by Bloomberg. We have used simplex optimization method to find the debt level that maximizes firm value. Then, we compare the estimated debt with real debt of companies using statistical nonparametric Mann-Whitney. The results indicate that $63 \%$ of companies do not show a statistically significant difference between the real and the estimated debt.

\section{Keywords}

Bankruptcy Cost, Capital Structure, Trade-Off, Dynamic Analysis

\section{Introduction}

If there is one subject that both fascinates and frustrates financial theorists and researchers, it is capital structure. It is the basic question that all financial managers should be able to answer: How much debt and how much equity should my company have? Even although these and other questions have occupied economists for a long 
time, we are far from that being answered. Most of the empirical literature on firms' capital structure analyzes this issue within a static framework. Since the seminal papers of Modigliani and Miller (referred to as MM propositions from now on) written between 1958 and 1963 [1] [2], much works try to understand "how" to look at the problem and the results of their work were somewhat counterintuitive.

The resulting research that stemmed from the MM propositions yielded two different schools of thought. The first avenue, which directly followed the MM proposition line, has been attempting to find a relationship between the tax benefit of debt, the cost of bankruptcy and the optimal level of debt versus equity of a firm. This line of thought is commonly known as Trade-Off Theory. The other school of thought put forth by Myers [3] states that there is no optimal level of debt versus equity because transaction costs and asymmetrical information erase any value of tax benefit to debt. Under these circumstances, companies prefer internal financing and will only move to debt and finally equity issues as they run out of option in their preferred means of financing. This line of thought is commonly known as the Pecking Order Theory. In general, mathematical models put forth have been Trade-Off model related, as the Pecking Order Theory is more a descriptive theory of observed behavior of companies.

There have been hundreds of deterministic models presented since 1958, starting with the leverage gains model presented by Modigliani and Miller [2] and improved by Miller [4]. It may be noted that research on the Trade-Off theory have evolved over time. Initially focused on the trade-off static - that is, with a target leverage ratio immovable and that the company tends to achieve. Now focus on the Trade-Off dynamic. In this line, we find predictive models such as Fischer, Heinkel and Zechner [5] and Titman and Tsyplakov [6] they seek leverage targets on the move, which has led to the generation of complex models.

The objectives of this study are as follows: First, develop a model for calculating the optimal level of debt, which adjust the cost of funds (both debt and equity) for bankruptcy risk that each monetary unit of debt brings to cash flow of the company. Second, apply the model to real data of the companies included in the Dow Jones Industrial Average (DJIA) to check the robustness of it.

This paper is organized as follows. Section 2 provides an overview the most outstanding papers on capital structure including bankruptcy costs in their models. Section 3 describes the dynamic model of capital structure developed. Section 4 describes the methodology and data used. Section 5 shows the findings. The final session discusses the overall conclusion of the study.

\section{The Trade-Off Models Calculating the Optimal Debt Level by Incorporating the Effect of the Cost of Bankruptcy}

\section{Selecting a Template}

Previous literature to estimate the cost of bankruptcy is extensive. One of the best examples is Altman [7] who investigated the bankruptcy costs, determining both the direct and indirect costs of bankruptcy. For costs used a regression on sales of ten years of the industry to which each firm owned and used the resulting to determine the expected sales of the company for the year under review. On the other hand, Kalaba et al. [8] presents a new methodology, quasilinear estimation, for efficiently estimating economic variables reflected in the prices of corporate securities. Ex ante bankruptcy costs are not directly observable, however, if these costs are sufficiently large, then current security prices are affected and bankruptcy costs can be indirectly measured. However, as argued Scherr [9] knowledge of bankruptcy costs was poor and did not permit any decisive conclusion regarding the trade-off theory. Studies of Altman [7] on loss of value at the time of bankruptcy are the most complete including a database to determine the value at risk of bankruptcy according to each industry. Leland [10] did some very interesting work that, although strictly theoretical, in our view, came closer to the mark of what an optimal capital structure model should be like. The author developed a set of formulas using as a starting point a simple company value that is determined by a diffusion process with constant volatility of rate of return. Leland then derived the optimal leverage ( $L^{*}=D / v$ where $D$ is debt and $v$ is the value of the company) maximizing the value of the company.

Through a complex system of simultaneous equations based on the following formulas:

$$
\begin{gathered}
C^{*}(V)=V[(1+X) h]^{1 / X} \\
D^{*}(V)=V[(1+X) h]^{-1 / X}\{1-k[(1+X) h]-1\} / r
\end{gathered}
$$




$$
v^{*}(V)=V\left\{1+(T / r)[(1+X) h]^{-1 / X}[X /(1+X)]\right\}
$$

where $X=2 r / \sigma^{2}$

$$
\begin{gathered}
m=[(1-T) X / r(1+X)]^{X} /(1+X) \\
h=[1+X+\alpha(1-T) X / T] m \\
k=[1+X-(1-\alpha)(1-T) X] m
\end{gathered}
$$

And $C^{*}$ is the optimal coupon for the debt, $D^{*}$ is optimal debt and $v^{*}$ is the optimal value of the company's assets, while $V$ is the value of the company, $r$ is the risk free rate, $\sigma^{2}$ is the volatility of the assets of the company, $T$ is the corporate tax rate and $\alpha$ is the costs related to bankruptcy. The solution to the simultaneous equations yields $L^{*}$, the optimal leverage. Unluckily, Leland's [10] research was purely theoretical, as the numbers used to test his theory were plug-ins based on what he considered industry averages. For example, he assumed a 50\% cost of bankruptcy, a number that doesn't really coincide with any of the research that people like Altman [7] have done. At the same time, the value of assets and the volatility of asset values, data required by Leland's equations, are not numbers that are easily found or measured.

Philosophov and Philosophov [11] came up with a very practical model, easy to understand by general financial practitioners as it was based on the easily recognizable discounted cash flow.

In this case, the cash flow was discontinuous at the point of bankruptcy:

$$
V\left(f, t_{b}\right)=\sum_{i=1}^{i<t_{b}} \frac{E_{i}(f)}{(1+d)^{i}}+(1-\delta) \sum_{i>t_{b}} \frac{E_{i}(f)}{(1+d)^{i}}
$$

The value $V$ of the company is a function of a number of factors $f$ and the moment of bankruptcy $t_{b}$. After bankruptcy, the cash flow suffers a reduction in value represented by the term $\delta$. The net present value of the company is determined by the estimated profit of the company, $E_{i}(f)$ up to the time of bankruptcy. After the time of ban kruptcy, the cash flow is diminished in $(1-\delta)$. Since the moment of bankruptcy is so important, it becomes paramount to the model to correctly determine said moment. To that effect, the authors use a Bayesian method to determine the probability and the moment of bankruptcy by a prognosis system developed by Philosophov and Philosophov [12] in a previous article. Using four factors for the prognosis of bankruptcy of the company (short term liabilities/total assets, retained earnings/total assets, EBITDA/total assets and interest payments/total assets) the authors determine that qualitative factors of debt, like the cost of servicing the debt or the maturity of the debt have a higher impact on the probability of bankruptcy of a company. Although the author's title for their research points to optimal capital structure, the article itself develops the prognosis of the probability of bankruptcy and the fit of different factors to determine said probability, but the optimal capital structure model itself is never truly tested. Furthermore, the discount rate of the cash flow of the company in the model is the same for before and after bankruptcy situations, which is counterintuitive and the interest rate seems to be exogenously derived, so changes in probability of default have no impact on interest rates. Finally, Hull [13] including the financial effect of the probability of bankruptcy in the perpetuity of the value of leverage gains. Hull [13] included the exogenous cost of riskless debt, $r f$, the exogenous cost of leveraged equity, $r u$, the endogenous cost of risky debt, $r d$ and the endogenous cost of leveraged equity. The author took the Miller [4] formula:

$$
G_{L}=\left[1-\frac{\left(1-T_{E}\right)\left(1-T_{C}\right)}{\left(1-T_{D}\right)}\right] D
$$

where $T_{E}$ is the personal tax rate on equity income, $T_{C}$ is the corporate tax rate, $T_{D}$ is the personal income tax rate on interest income and $D$ is the value of the company's debt. To improve the formula Hull [13] modifies it to represent a perpetuity where net value of leverage gains is given by the difference between the net present value of the leveraged company minus the net present value of the unleveraged company $\left(G_{L}=V_{L}-V_{U}\right)$. To do so, Hull [13] used the aforementioned rates to modify Miller's [4] formula so that:

$$
G_{L}=\left[1-\frac{\alpha r d}{r l}\right] D-\left[1-\frac{r u}{r l}\right] E_{U}
$$


where $\alpha$ represents $\frac{\left(1-T_{E}\right)\left(1-T_{C}\right)}{\left(1-T_{D}\right)}$ and where $r d<r u<r l$ and $D<E_{U} . E_{U}$ is the unleveraged value of the shareholder's invested capital. Thus, the side of the equation that represents $V_{U}$ (unleveraged value, right hand side) is generally negative (if $r u<r l$ then $1-\frac{r u}{r l}>0$ which multiplied by $-E_{U}$ gives us a negative value) while the side of the equation that represents $V_{L}$ (leveraged value, left hand side) is generally positive (if $r d<r l$ then $1>1-\frac{r u}{r l}>0$ and if $T_{E}>T_{D}$, which is a basic postulate of the benefit of debt, then $1>\alpha \frac{r u}{r l}>0$ and $D$ multiplied by the result would be a positive number).

In this fashion, Hull [13] attempts to include the effect of bankruptcy cost of debt in the calculation of leverage gains, also attempting to correct the lack of dynamic in Miller's formula by including the effects of increased leverage on the cost of financing and the risk of bankruptcy. The problem with Hull's formulas is that, despite the fact that it makes perfect sense, there is no clear explanation of what the endogenous cost of risky debt and the endogenous cost of leveraged equity are, or how to obtain them from observable data. At the same time, there is no clear link between the cost of bankruptcy and the endogenous cost of risky debt.

\section{Empirical Model Approach}

Let us set up a basic scenario for our model. We will start by looking at a simple company with many shareholders, no debt and one manager. For the time being we will forgo taxes. Under such circumstances, the value of the company will be represented by:

$$
V=-\operatorname{Kinv}_{0}+\sum_{t=1}^{\infty} \frac{E B I T D A_{t}}{(1+W A C C)^{t}}-\sum_{t=1}^{\infty} \frac{D E P_{t}}{(1+W A C C)^{t}}
$$

where $V$ is value of the company, WACC is the weighted average cost of capital, Kinv are the funds invested by the company either from its o own funds or from equity issues (we consider all funds in the company as belonging to the shareholders, so we see little difference between money coming from shareholder or money coming from the company's operations) EBITDA is the earnings before interest payments, taxes, depreciation and amortization and $t$ is the time period. Since we are looking for the sustainability of the investment over time, we include the depreciation $(D E P)$ as a cost as it generates de funds necessary to keep the investment operating indefinitely. Since there is no debt, the WACC and the company's return on equity would be the same. Thus, the company invests an amount Kinv at time zero in equipment, which allows the company to generate a cash flow represented by $\sum_{t=1}^{\infty} \frac{E B I T D A_{t}}{(1+W A C C)^{t}}-\sum_{t=1}^{\infty} \frac{D E P_{t}}{(1+W A C C)^{t}}$. So long as the investment is profitable, the net present value of the cash flow from the investment will be higher than the funds invested and the company's value will be positive.

Let us now include debt in the equation to allow this company manager to decide between using his shareholder's money or financing the investment. For simplicity we will assume there is only one type of debt: unsecured bond or bank debt. From a cash flow perspective to this manager, the company's value function would look as this:

$$
V=- \text { Kinv }_{0}+\sum_{t=1}^{\infty} \frac{E B I T D A_{t}}{(1+W A C C)^{t}}-\sum_{t=1}^{\infty} \frac{D E P_{t}}{(1+W A C C)^{t}}-\sum_{t=1}^{n} \frac{A M R T_{t}}{(1+W A C C)^{t}}-\sum_{t=1}^{n} \frac{D_{t} i}{(1+W A C C)^{t}}
$$

were $A M R T$ is the amortization of the debt contracted and is described as a function of the original debt at time 0 divided by the number $n$ of payments contracted: $A M R T=D_{o} / n$. The cost of interest payments is represented by the debt at time $t\left(D_{t}\right)$ multiplied by the debt interest rate $i$. Now Kinv represents the portion of invested funds that comes from equity, be it company funds or new equity issue. Since now there is debt, the WACC would be represented by the well-known function $W A C C=\frac{E}{D+E} k+\frac{D}{D+E} i$ were $E$ is the book value of equity, $D$ is the face value of debt, $k$ is the return on common equity and $i$ is the interest rate on debt. In turn, 
$k$ is represented by the Capital Asset Pricing Model in the formula $(k=r+\beta(r m-r)$ where $r$ is the risk free rate, $r m$ is the average stock market return and $\beta$ is the beta of the company's stock). In turn, the $\beta$ is also affected by debt levels, so, an unleveraged $\beta$ will have to be calculated to include the appropriate effect of increased debt in the calculation of the return on equity $k$ (see Hamada [14]) We need to unleverage $\beta$ for our purposes, as it will allow us to search for an optimal debt level that is unencumbered by the effect of the company's current debt level. Notice that we use both equity and debt returns to determine the WACC, despite the fact that we are looking at the return for the shareholders. This point comes back to the manager. Remember that the manager has no way of determining neither the required return on equity nor the tax profile for each of his shareholder. He, therefore, needs to maximize the value of the company which, he assumes, will result in a better return for the shareholders. However, from the manager's perspective, the value of the company will depend in part on how well he can finance its operations. Thus, for the manager, his discount rate of cash flows is the weighted average of both equity and debt costs. Thus, if the manager can find a "cheaper" way of financing operations, he brings more value to the shareholders. Notice also that, with the inclusion of debt in our model, we have turned it into a two-step model. The first step is to determine the optimal investment necessary to produce the company's estimated cash flow. The second step is to determine how to finance this. Most models stop here and take the debt interest rate as an exogenous variable and try to determine a value effect of bankruptcy as an addition to the model (see Philosophov and Philosophov [11]). In our view, the debt interest rate is an exogenously determined variable, but based on one main endogenous component, mainly the company's probable value loss at bankruptcy.

\subsection{Interest Rate Dynamic Model}

We have found very few research papers that use an interest rate that is determined internally by the model, as common practice is to assume the interest rate as exogenous. The works of Leland [10] and Leland and Toft [15] are the best we have come across, using contingent claims analysis in a similar fashion to Merton [16] to determine an interest rate $R$.

where variable $K$ is defined as:

$$
R(C / V)=C / D(V)=r K(C / V)
$$

$$
\begin{gathered}
K(C / V)=\left[1-(C / V)^{X} K\right]^{-1} \\
X=2 r / \sigma^{2} \\
K=[1+X-(1-\alpha)(1-T) X] m \\
m=[(1-T) X / r(1+X)]^{X} /(1+X)
\end{gathered}
$$

where $C$ is the debt coupon, $V$ is the value of the company's assets, $r$ is the risk free rate, $\sigma^{2}$ is the volatility in the value of the assets, $T$ is the corporate tax rate and $\alpha$ is the costs associated with bankruptcy. Unluckily, as with most research that follows this particular line of inquiry, the work done is mostly theoretical and not tested on real data. Another problem that this line of inquiry faces is that the variables used by these models are not easily observed or easy to measure.

Merton [16] in his paper "The Pricing of Corporate Debt: The Risk Structure of Interest Rates", used the Black and Scholes [17] methodology to determine the value of assets and the implicit volatility in the price of an option represented by the equity of a company. As such, Merton [16] calculates the distance to the point of bankruptcy, measured in standard deviations, as:

$$
D Q_{\text {MERTON }}=\frac{\ln \left(V_{A} / D\right)+\left(r-\frac{1}{2} \sigma_{A}^{2}\right)(T-t)}{\sigma_{A} \sqrt{T-t}}
$$

where $V_{A}$ is the company's market value of assets, $D$ is the total amount of debt, $(T-t)$ is the remaining time to the due date of debt, $\sigma_{A}$ is the volatility in the value of the assets, $\sigma_{A}^{2}$ is the standard deviation in the value of assets and $r$ is the risk free rate. 
The main problem with Merton's formula is that the market value of assets of a company is not an easily observable data. Even calculating the market value of assets would be cumbersome. Obtaining the volatility and standard deviation in the market value of assets would require that such a cumbersome calculation be repeated enough times to make the data reliable. This means that most research based on similar formulas, like Leland [10] and Leland and Toft [15] are based on randomly defined values or on variables used as proxies to the market value of assets. In Bystrom [18] attempted to simplify Merton's formula by using proxies and measuring the correlation between Merton's results and the results of Bystrom's simplified formula. Bystrom got rid of the drift term, as it was generally very close to zero and used a one period debt. He then restated $\sigma_{A}$ as $\frac{\sigma_{E} V_{E}}{V_{A}}$ where $\sigma_{E}$ is equity volatility and $V_{E}$ is the market value of equity. Cleaning up the formula and replacing $D / V_{A}$ for $L$, we have Bystrom's [18] simplified formula for the distance to bankruptcy:

$$
D Q_{\text {BYSTROM }}=\frac{\ln (1 / L)_{E}}{\sigma_{E}(1-L)}
$$

Finally, Bystrom determined that $V_{A}=V_{E}+D$ so $L$ can also be expressed as: $L=\frac{D}{V_{E}+D}$.

Bystrom's approximation to Merton's formula showed a 99.9\% correlation with Merton's formula, which allows us to use easily obtainable data to calculate the distance to default.

We also used Altman and Kishore [19] research on bond default and recovery of value at the time of default, as well as the periodic reports on the loss of value of defaulted bonds (Altman and Suresh [20]) to determine the cost of bankruptcy. Thus, we have also modeled the debt interest rate function $i$ based on Bystrom's [18] simplification of Merton's [16] formula to determine the company's distance to bankruptcy. Simply put, the debt interest rate is determined by the risk free rate $r$, the cumulative area under the normal distribution curve (known colloquially as the $z$-value) of the distance to bankruptcy (measured in standard deviations from the mean) and the percentage of the value of the company lost at bankruptcy $R$, so that:

$$
i=r+\left(1-\left(N\left(\frac{\ln (1 / L)}{\sigma_{E}(1-L)}\right)\right)\right) R
$$

where $L$ is the $D / D+E$ ratio, $\sigma_{E}$ is the volatility of the company's equity, which is used as a valid approximation to the volatility of the company's asset return and $N$ is the cumulative normal distribution. This distance to bankruptcy estimation is but an approximation to Merton's [16] more complex formula, but it will serve for the purpose of our analysis and, furthermore, it uses only observable parameters, so it eliminates the use of unknown variables. Bystrom's [18] research actually concludes that the correlation between Merton's [16] original formula and the simplified one estimated by Bystrom himself is $99.9 \%$ so the difference between both is very small. We will refer to the term $1-\left(N\left(\frac{\ln (1 / L)}{\sigma_{E}(1-L)}\right)\right)$ as the probability of bankruptcy.

Looking at Equation (1.2), we notice that the debt value is divided into two components: one represented by the present value of all payments of the principal of the debt and a second one that represents the net present value of the interest payments on the outstanding debt. Again, since we are looking at this cash flow from the manager's perspective, both terms are negative as they detract from the shareholder's cash flow. Furthermore, since the principal of the debt has been broken up into an n number of payments to be paid in an n number of periods, both components of debt are meaningful only up to the nth period since at time $n+1$ all the debt will be repaid and thus both terms will equal zero. At this point in the model, we have yet to include the government's silent participation in our company's cash flow. The addition of corporate taxes has two opposing effects. On the one hand it subtracts from the company's cash flow leaving the inflow as $\operatorname{EBITDA}(1-T)$ were $T$ is the corporate tax rate. On the other hand, it generates two tax shields: one from the depreciation inherent to the investment itself and a second shield from the interest paid on debt. Thus, our formula would now look as follows:

$$
V=-\operatorname{Kinv}_{0}+\sum_{t=1}^{\infty} \frac{\operatorname{EBITDA}_{t}(1-T)}{(1+W A C C)^{t}}-\sum_{t=1}^{\infty} \frac{D E P_{t}(1-T)}{(1+W A C C)^{t}}-\sum_{t=1}^{n} \frac{A^{2} T_{t}(1-T)}{(1+W A C C)^{t}}-\sum_{t=1}^{n} \frac{D_{t} i(1-T)}{(1+W A C C)^{t}}
$$


Since we are including taxes, we also need to revisit the calculation of the return on equity $k$ and the WACC. Recall that we talked earlier of the effect of debt on $\beta$ and the need of calculating an unleveraged $\beta$. The tax effect on debt will also have an effect on $\beta$ so that leveraged $\beta=$ unleveraged $\beta\left(1+\left((1+T) \frac{D}{E}\right)\right)$ were $T$ represents the corporate tax rate, $D$ the debt and $E$ the equity. This will allow us to account for changes in the return on equity $k$ due to increases in debt levels. The calculation of WACC will also have to take into account the lower cost of debt due to the tax effect on interest payments. This would result in a $(1-T)$ adjustment to the debt interest rate $i$, such that the new equation would be: $W A C C=\frac{E}{D+E} k+\frac{D}{D+E} i(1-T)$ effectively reducing the WACC and thus increasing the net present value of future cash flows (generating a second order tax shield which is not directly seen in the cash flow per se, but rather through the present value of said cash flows).

What we now have is a value based function that can be maximized to find the optimal debt level for the company, but that also adjusts the cost of funds (both equity and debt) to account for the added risk that debt brings to the cash flows of the company.

\subsection{Maximization Problem}

As we mentioned earlier, ours is a two-step model where the determination of the necessary investment, Kinv, is determined prior to the value maximization process of determining how much debt and how much equity will be used to finance the investment. Therefore, the EBITDA of the company, as well as the depreciation, is calculated and set prior to the maximization process. The final step is to look for the optimal debt level required by the company to finance its operations. We define the optimal debt level as that which maximizes the net present value of the company, as per Formula (1.4). The increase in the net present value of the company when maximizing the debt level comes from the increase in the value of tax shields as more debt is added, versus the added cost of said debt. As such, the increase in debt will increase the probability of bankruptcy to a point when the addition of further debt will increase the cost of debt over and above the benefit of the marginal tax shield.

So we see that the relationship between debt and company value is an inverted $U$ shaped curve, where the higher interest rate resulting from the increase in the probability of bankruptcy of additional debt is lower than the positive effect of a lower WACC and the $(1-T)$ effect on the left hand side of the curve (the upward sloping side) while the right hand side (downward sloping side) shows an interest rate effect that out-weights the lower WACC and $(1-T)$ effect.

The parameters of our maximization procedure are the following:

1. The amount of the investment needed by the company, Kinv, is exogenous to the maximization process of the capital structure. That is to say that the level of investment is not conditioned by the source of the funds.

2. Equity, $E$, has to be positive and at least 1 . This has to do with the social construct of companies in the North American market, where the creation of a company requires that equity be supplied (debt is not a requirement to create or incorporate a company in the US).

3. Debt, $D$ and Equity, $E$, as well as the value of the company, $V$, must be positive.

4. The probability of bankruptcy should not exceed $5 \%$.

The fourth parameter requires some explanation. Usually, the model should be able to calculate interest rates from bankruptcy probability levels of $0 \%$ to $100 \%$. However, if we look at the formula, at $100 \%$ of probability of bankruptcy, the formula turns into $1 \mathrm{R}$ and therefore the cost of the debt represented by the probability of bankruptcy is equal to the expected loss in value of the debt at the moment of bankruptcy as determined by Altman and Suresh [20].

Nevertheless, the use of Altman and Suresh's data to determine the interest rate sets a limit to the probability of bankruptcy that our interest rate model can predict.

If we look at the classification of debt as Standard and Poor's, we see that debt is classified from AAA which SandP itself describes as "Extremely strong capacity to fulfill its financial obligations", all the way to $D$ "In default of its financial obligations”.

As such, any debt rated below $C$ would be encompassed in Altman and Suresh's [20] report and would, therefore, be affected by the discount reported by Altman and Suresh [20] in its entirety. However, as we look at Altman and Suresh's [20] report, we see that the probability that a CCC rated company default after 10 years of 
operations is $4.70 \%$. This is the reason that we used a $5 \%$ cut-off for the probability of default. Anything with a higher probability of default would be rated $D$ and, as we said before, subject to the full discount reported by Altman and Suresh [20]. A further review of Altman and Suresh [20] shows that the mortality rate (default) of high yield bonds (that is to say, bonds rated D) for 2006 was $0.76 \%$ and projected $2.50 \%$ for 2007 and $3.72 \%$ for 2008. Furthermore Altman and Suresh [20] show that the mortality ratio since 1972 for high yield bonds has only surpassed the $5 \%$ mark five times and all of them during recessions.

\section{Methodology and Data}

To test our model, we used it to try to determine the optimal debt level (short and long term straight debt) of the companies that made up the Dow Jones Industrial Average (DJIA) in 2007 and compare it to their real debt between the years 1996 and 2006. However, since this is an EBITDA based model we had to eliminate from the sample all financial companies (this takes out of the sample, American Express, J. P. Morgan Chase, Citigroup and AIG) leaving 26 companies on the sample group. Furthermore, for the sake of our study, General Motors was also eliminated as it had a negative shareholder's equity in 2006 and negative EBITDA in 2005, leaving the sample at 25 companies. We decided to use the period from 1996 to 2006 because if we started in 1995 we would have had to eliminate also Microsoft and Honeywell (because both the $\beta$ and the $\sigma_{E}$ are calculated from data from the previous 10 years and both companies did not list back in 1985). We used consolidated year end 1996 to 2006 numbers as reported in Bloomberg.

The test assumes that the book value of debt and the book value of equity represent the capital raised by the company to meet their investment needs. We understand that some capital structure prediction models use market value of both equity and debt. Welch [21] goes as far as to state that book value of equity holds "little economic significance" (Welch [21]). However, for the sake of our model, the book value of equity and the face value of debt are the right values to use. Our model uses the return on equity (k) and the interest rate (i) to determine the company's optimal debt level that maximizes its net present value. But the market value of equity already includes $(\mathrm{k})$ since the market value of equity is nothing more than the net present value of the market's best estimate of the company's future cash flows net of current debt. Thus, the market value of equity presupposes a given debt level. Nevertheless, our purpose is to try to determine the optimal level of debt of the company so, how can we do this using a variable like market value of equity? Logically, every time we change the debt level to try to maximize the net present value of the company, we would also have to change the market value of equity to account for a different debt level.

More important, changes in the market value of debt or equity have no impact on the company's cash flow. For the company to benefit from the increase in market values it would need to issue either debt or equity, which would be reflected in the book value of the company, bringing us back to the book value of equity and debt as the proper measure for our purposes. The investment financed with either debt or equity (or a mixture of both) generates an EBITDA and a depreciation which are constant over time. The assumption behind this is that all capital was invested in productive assets, operating at capacity and no new capital will be raised until the next year (any new capital raised would warrant a new calculation). Thus, we can calculate

$\sum_{t=1}^{\infty} \frac{E B I T D A_{t}}{(1+W A C C)^{t}}-\sum_{t=1}^{\infty} \frac{D E P_{t}(1-T)}{(1+W A C C)^{t}}$ as a perpetuity of both EBITDA and depreciation, assuming a cero growth rate. Thus, $\sum_{t=1}^{\infty} \frac{E B I T D A_{t}}{(1+W A C C)^{t}}=\frac{E B I T D A}{W A C C}$ and $\sum_{t=1}^{\infty} \frac{D E P_{t}(1-T)}{(1+W A C C)^{t}}=\frac{D E P(1-T)}{W A C C}$. This is a simplification necessary to reduce the workload to run our test from thousands of calculations to hundreds of calculations.

\subsection{Clarification on the Calculations}

The amortization of debt and the interest payments are calculated over the weighted average length of the company's debt as reported in their 2006 10-K and then brought to present value using the company's WACC. The average 1996 to 2006 tax rate paid by the company is used as corporate Tax (T).

Each company's $\beta$ is calculated as the correlation between the monthly log normal returns of the stock and the monthly log normal returns of the DJIA divided by the variation in the monthly log normal returns of the DJIA. 
The equity volatility $\left(\sigma_{E}\right)$ is calculated as the standard deviation of the monthly log normal returns of each stock. Ten years of previous data are used to determine both the $\beta$ and the equity volatility for each of the years in the test. For $\mathrm{k}$ we take the compounded annual return on the Dow Jones Industrial ${ }^{1}$ for the period 1990 to 2006, which is $10.2 \%$. The percentage of the company's value lost at bankruptcy $(\mathrm{R})$ is calculated as [1-bond recovery rate] which, in turn, is taken from Figure 21 of Altman and Suresh's [20]: "High Yield Bond Default and Return Report", while the risk free rate is the 5-year or 2-year Treasury Note or the 10- or 30-year Treasury Bond (whatever best matches the average length of the company's debt) as of the end of the previous year to the year of calculation (so for our 2006 calculation we use the end of year 2005 bond or note). The model is then run through a simplex method with one single constraint (probability of bankruptcy for any given year cannot exceed 5\%) maximizing the net present value of the company. This gives as a result an estimated amount of debt the company should have had if it wanted to maximize its value. The eleven results that are obtained for each company from the optimization algorithm, together with the real debt levels reported, are afterwards run through a Mann-Whitney hypothesis test at a 99\% confidence interval to determine if there is a statistically significant difference between the median target debt levels obtained from the model and the median real debt levels reported by each company. The reason we use a non-parametric test like the Mann-Whitney test instead of a normal hypothesis test is because many of the company's real debt show a distinct non-normal distribution when tested with the Anderson-Darling Normality test. The assumption behind our use of the Mann-Whitney test is that, due to the competitive level of the market, companies will attempt to optimize their debt levels to maximize their value. Therefore, for our test, the debt levels we find in the real world are deemed as optimal and the model's predictability of real debt levels is considered a gauge of the models effectiveness.

\subsection{Drawbacks of the Sample}

There are a number of concessions we have had to make either due to lack of information or in order to facilitate the performance of our test. For the purpose of determining a recovery rate from Altman and Suresh [20] to calculate the interest rate for each model, $40 \%$ of the companies were catalogued as general manufacturing, $24 \%$ as miscellaneous industries, $16 \%$ as communications, $8 \%$ as retailing, $4 \%$ as energy and $8 \%$ as conglomerates. We consider that one of the main problems we faced conducting these tests came from shortcomings in determining the recovery rate for each company. We would not have been able to conduct the test were it not for the Altman and Suresh [20] tables, but they lacked proper industry classifications and were calculated for a compounded 1971-2006 period. This did not allow us to properly include in our calculations the subtleties of each industry and of each year. For example, there was no "software" classification, so we had to list Microsoft under "communications" or no "chemical" so Pfizer, Merck, etc. had to list as "general manufacturing". This explains the percentage of companies that were listed under the "general manufacturing" classification. The use of maturity periods for 2006 in all calculations from 1996 to 2006 posed a second possible source of discrepancy. Unluckily, we could find no report of maturity periods for the 25 companies in our sample, so we actually had to go to each company's 10-K for 2006 and "estimate" a maturity period (most 10-K reports give a range of maturities for same interest rate debt, so we actually had to use averages and medians to calculate a weighted average maturity). If maturity period for other years differed significantly from these, the model would have miscalculated for those years. Also, the time required to properly calculate every single cash flow for each of the 25 companies for each of the 11 periods under observation for the purpose of our test would have required an enormous amount of time. Thus, we used a simplification by resorting to perpetuity to calculate each net present value. We understand the limitations of our simplification and concede that the predictive capacity of our model could be improved by a thorough calculation of a company's cash flows. Finally, our optimization model used static maturity periods and risk-free rates so, in essence, there is a chance that there is another, better, solution at a longer or shorter maturity period. The downside to this approach is that it would exponentially complicate the model, as further constraints would have to be included.

\section{Empirical Model Results}

The results of the Mann-Whitney tests show that, at a 99\% confidence interval, $63 \%$ of the companies tested had no statistically significant difference between the median target debt calculated by our model and the median real debt for the company as reported in Bloomberg (See Table 1).

${ }^{1}$ Data retrieved from http://www.djindexes.com/mdsidx/index.cfm?event=indexHistory on November 19 th 2007. 
Table 1. Results of the Mann-Whitney test from empirical model.

\begin{tabular}{|c|c|c|c|c|c|c|c|}
\hline Company & W-Statistic & P-Value & $\mathrm{P}>0.01$ & Company & W-Statistic & P-Value & $\mathbf{P}>0.01$ \\
\hline Alcoa Inc. & 150.0 & 0.1310 & Equal & McDonalds Cp & 82.0 & 0.0039 & Not Equal \\
\hline Boeing Co. & 167.0 & 0.0086 & Not equal & 3M Company & 66.0 & 0.0001 & Not Equal \\
\hline Caterpillar Inc. & 187.0 & 0.0010 & Not equal & Altria Group Inc. & 132.0 & 0.7427 & Equal \\
\hline Du Pont & 122.0 & 0.7928 & Equal & Merck Co Inc. & 104.0 & 0.1486 & Equal \\
\hline Walt Disney-Disney Co. & 108.0 & 0.2372 & Equal & Microsoft Cp. & No Significant & No Significant & \\
\hline Gen Electric Co. & 143.0 & 0.2934 & Equal & Pfizer Inc. & 111.0 & 0.3246 & Equal \\
\hline Home Depot Inc. & 68.0 & 0.0001 & Not equal & Procter Gamble Co. & 128.0 & 0.9476 & Equal \\
\hline Honeywell Intl Inc. & 142.0 & 0.3246 & Equal & AT and $\mathrm{T}$ Inc. & 121.0 & 0.7427 & Equal \\
\hline Hewlett Packard Co. & 166.0 & 0.0104 & Equal & United Tech. & 101.0 & 0.1007 & Equal \\
\hline Intl Business Mach & 187.0 & 0.0001 & Not equal & Verizon Commun. & 159.0 & 0.0356 & Equal \\
\hline Intel Cp. & 68.0 & 0.0001 & Not equal & Wal Mart Stores & 129.0 & 0.8955 & Equal \\
\hline Johnson and Johnson Dc. & 66.0 & 0.0001 & Not equal & Exxon Mobil Cp. & 66.0 & 0.0001 & Not Equal \\
\hline Coca Cola Co. & 95.0 & 0.0418 & Equal & & & & \\
\hline
\end{tabular}

\section{Conclusions}

From our results, we can draw the following conclusions:

1. We created a simple model that can be used by any financial officer to determine the optimal level of debt of a company. The model used Bystrom's [18] simplification of Merton's [16] contingent claims formula to determine the distance to default and generate a dynamic interest rate based on the leverage of the company. Our model shows adequate levels of prediction as the Mann-Whitney test show. In the process of creating our model, we have used a predictive formula to determine an interest rate. Although our calculation only takes into consideration the time value of money (represented by the risk free rate) and the risk value of bankruptcy, is gives a solid base to start building a more complex model that incorporates other risks predictive level.

2. Our model finally does away with one of the main criticisms of Trade-Off theory. In the words of Stuart Myers: "The tradeoff theory cannot account for the correlation between high profitability and low debt ratios" (Myers [22]). Our calculations of optimal debt for Microsoft between 2002 and 2006, using a Trade-Off model, resulted in zero debt, proving that Trade-Off can explain the correlation between high profitability and low debt ratios.

3. The strong difference between the debt level calculated by our model and the actual level of debt that some of the companies in our sample had, like 3M, Johnson and Exxon, seems to confirm the results of Fischer et al. [5] that found that companies had a "region of no recapitalization" where their capital structures can vary considerably from the optimal structure.

\section{References}

[1] Modigliani, F. and Miller, M.H. (1958) The Cost of Capital, Corporation Finance and the Theory of Investment. American Economic Review, 48, 261-297.

[2] Modigliani, F. and Miller, M.H. (1963) Corporate Income Taxes and the Cost of Capital: A Correction. American Economic Review, 53, 433-443.

[3] Myers, S.C. (1984) Capital Structure Puzzle. The Journal of Finance, 39, 575-592. http://dx.doi.org/10.2307/2327916

[4] Miller, M.H. (1977) Debt and Taxes. The Journal of Finance, 32, 261-275.

[5] Fischer, E.O., Heinkel, R. and Zechner, J. (1989) Dynamic Capital Structure Choice: Theory and Tests. The Journal of Finance, 44, 19-40. http://dx.doi.org/10.1111/j.1540-6261.1989.tb02402.x 
[6] Titman, S. and Tsyplakov, S. (2007) A Dynamic Model of Optimal Capital Structure. Review of Finance, 11, $401-451$. http://dx.doi.org/10.1093/rof/rfm017

[7] Altman, E.I. (1984) A Further Empirical Investigation of the Bankruptcy Cost Question. The Journal of Finance, 39, 1067-1089. http://dx.doi.org/10.1111/j.1540-6261.1984.tb03893.x

[8] Kalaba, R., Langetieg, T., Rasakhoo, N. and Weinstein, M. (1984) Estimation of Implicit Bankruptcy Costs. The Journal of Finance, 39, 629-642. http://dx.doi.org/10.1111/j.1540-6261.1984.tb03651.x

[9] Scherr, F.C. (1988) The Bankruptcy Cost Puzzle. Quarterly Journal of Business and Economics, 27, 147-179.

[10] Leland, H.E. (1994) Corporate Debt Value, Bond Covenants and Optimal Capital Structure. The Journal of Finance, 49, 1213-1252. http://dx.doi.org/10.1111/j.1540-6261.1994.tb02452.x

[11] Philosophov, L.V. and Pilosophov, V.L. (2005) Optimization of a Firm's Capital Structure: A Quantitative Approach Based on a Probabilistic Prognosis of Risk and Time of Bankruptcy. International Review of Financial Analysis, 14, 191-209. http://dx.doi.org/10.1016/j.irfa.2004.06.010

[12] Philosophov, L.V. and Philosophov, V.L. (2002) Corporate Bankruptcy Prognosis. An Attempt at a Combined Prediction of the Bankruptcy Event and Time Interval of Its Occurrence. International Review of Financial Analysis, 11, 375406. http://dx.doi.org/10.1016/S1057-5219(02)00081-9

[13] Hull, R. (2007) A Capital Structure Model. Investment Management \& Financial Innovations, 4, 8-24.

[14] Hamada, R.S. (1969) Portfolio Analysis, Market Equilibrium and Corporation Finance. The Journal of Finance, 24, 13-31. http://dx.doi.org/10.1111/j.1540-6261.1969.tb00339.x

[15] Leland, H.E. and Toft, K.B. (1996) Optimal Capital Structure, Endogenous Bankruptcy and the Term Structure of Credit Spreads. The Journal of Finance, 51, 987-1019. http://dx.doi.org/10.1111/j.1540-6261.1996.tb02714.x

[16] Merton, R.C. (1974) On the Pricing of Corporate Debt: The Risk Structure of Interest Rates. The Journal of Finance, 28, 449-470.

[17] Black, F. and Scholes, M. (1973) The Pricing of Options and Corporate Liabilities. The Journal of Political Economy, 81, 637-654. http://dx.doi.org/10.1086/260062

[18] Bystrom, H.N. (2006) Merton Unraveled: A Flexible Way of Modeling Default Risk. The Journal of Alternative Investments, 8, 39-47. http://dx.doi.org/10.3905/jai.2006.627849

[19] Altman, E.I. and Kishore, V.M. (1996) Almost Everything You Wanted to Know about Recoveries on Defaulted Bonds. Financial Analysts Journal, 52, 57-63. http://dx.doi.org/10.2469/faj.v52.n6.2040

[20] Altman, E.I. and Suresh, R. (2007) Special Report on Default and Returns in High-Yield Bond Markets. http://people.stern.nyu.edu/ealtman/2006\%20Review-Market\%20Outlook.pdf

[21] Welch, I. (2002) Columbus’ Egg: The Real Determinant of Capital Structure. National Bureau of Economic Research, Cambridge. http://www.nber.org/papers/w8782

[22] Myers, S.C. (2001) Capital Structure. Journal of Economic Perspectives, 15, 81-102. http://dx.doi.org/10.1257/jep.15.2.81 
Scientific Research Publishing (SCIRP) is one of the largest Open Access journal publishers. It is currently publishing more than 200 open access, online, peer-reviewed journals covering a wide range of academic disciplines. SCIRP serves the worldwide academic communities and contributes to the progress and application of science with its publication.

Other selected journals from SCIRP are listed as below. Submit your manuscript to us via either submit@scirp.org or Online Submission Portal.
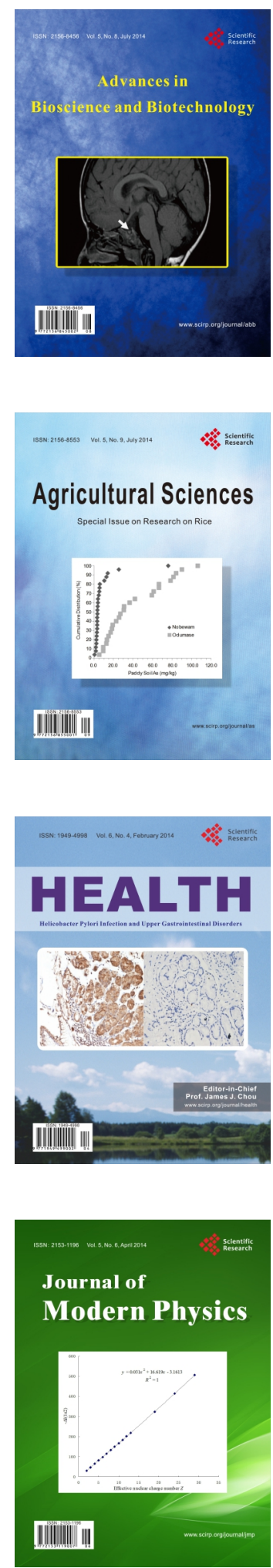
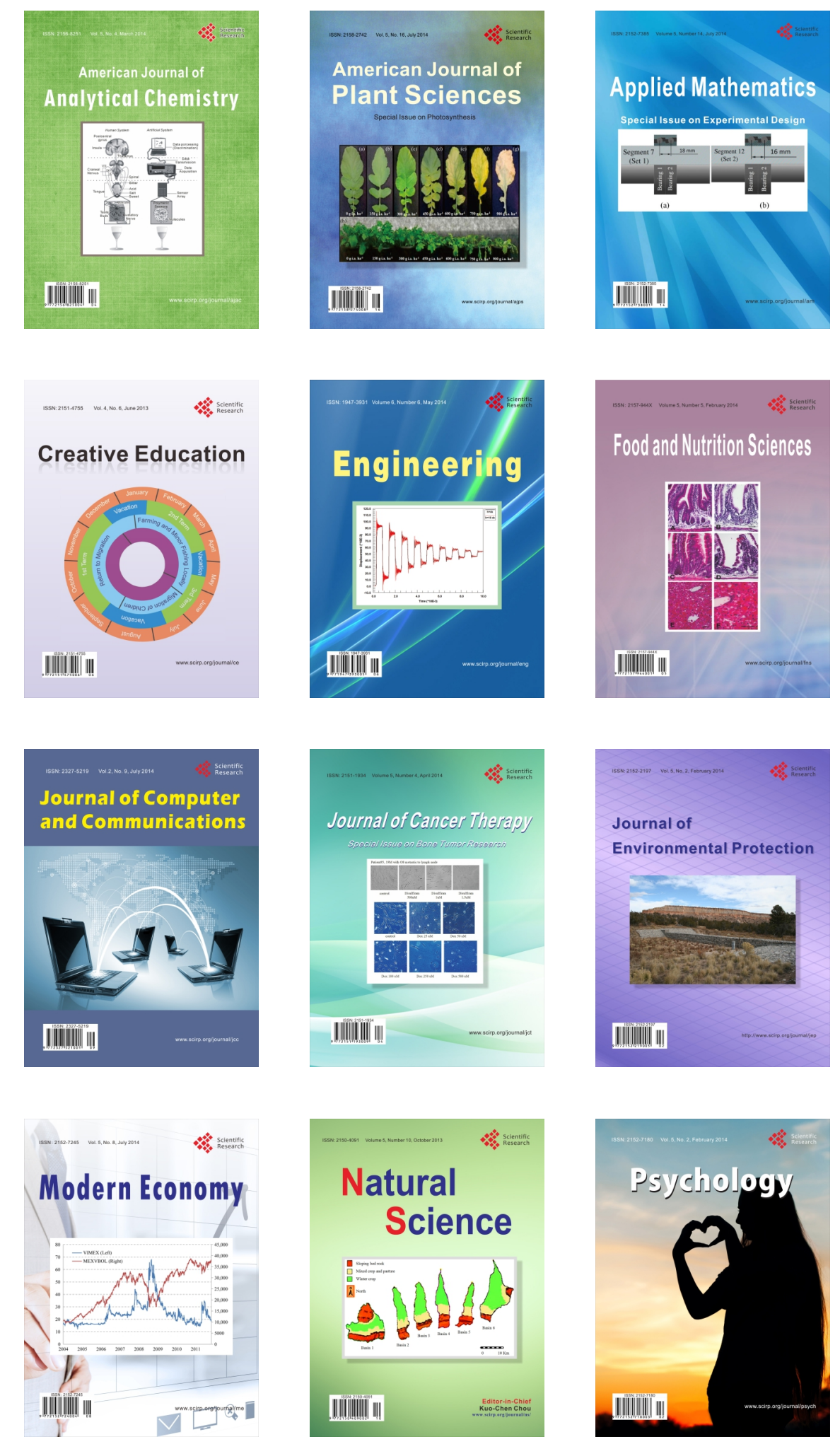